\title{
Narrative accounts of recovering at home after heart surgery
}

\author{
three vanishing scars \\ Forcefully remind me \\ of my mortality \\ what if my heart ... \\ what if my chest ... \\ how would I ...
}

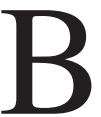
odily markings, sensations and feelings of vulnerability following heart surgery often permeate patients' thoughts. It is during the home period of recovery that patients begin to ruminate about what can be a traumatic and life-changing event. And yet, the home phase of recovery following surgery receives the least amount of attention in the cardiovascular literature. In addition to introspection during this phase, patients must assume a significant and active role in terms of self-management ${ }^{1}$ related to exercise, diet, medication and stress management, as well as adhering to guidelines concerning lifting, driving and sexual activity.

This article presents the results of an arts-informed narrative study of patients' experiences of the home period of recovery. Sixteen adults, 59 to 85 years of age, scheduled for coronary artery bypass graft and/or valve repair or replacement were recruited from a preoperative clinic. Individual interviews were conducted at 48-96 hours following surgery, and between 4-6 weeks following discharge. The methodological approach is new, and extensive details of the analytic and creative process appear elsewhere. ${ }^{2}$

To highlight the experiential qualities of patients' stories, we translated the study results into poetry and photographic images. The first author extracted words and phrases from inter-

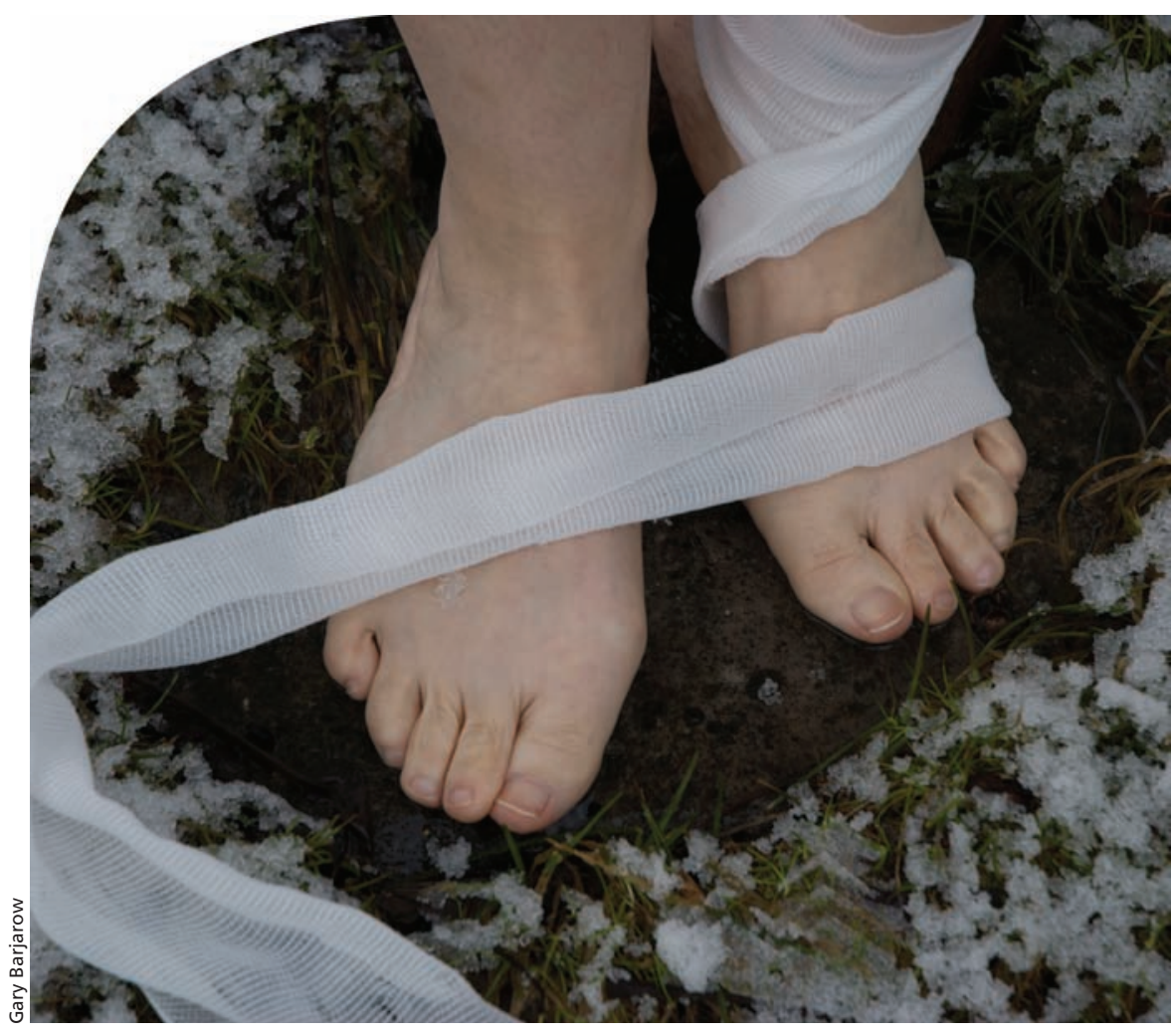

Image 1

views, and compiled them into poetry. The research team derived concepts from the patients' stories that informed the images, which metaphorically represent participants' experiences. The photographed subjects are volunteers and are not the actual research participants. These images provide viewers with an immediate and sensory lens to enter into the patient's journey of heart surgery and recovery.

The 13 poems and images, which follow the patient's journey through surgery and recovery, were originally displayed in 2011 at Toronto General Hospital and at the International Con- gress of Qualitative Inquiry in the United States. This article highlights three of those poems and four images concerning the first six weeks following discharge.

Image 1 focuses on the feet, the only body part visible in the intensive care bed, where the person is almost completely concealed by a heating blanket, iodine, and tubes and wires. In this image, the feet metaphorically represent the way that patients undergoing cardiovascular surgery become marked and carry their experiences of heart surgery with them throughout their life. 


\section{Thrown to the wolves}

This poem is based on participants' descriptions of engaging in self-management behaviors. Once participants returned home, they detailed their feelings of insecurity as they struggled to interpret and apply strict regimens to the particularities of their own bodies, lives and homes. The figure in Image 2 reflects this uncertainty as he stands alone in a boat where the horizon is barely visible.

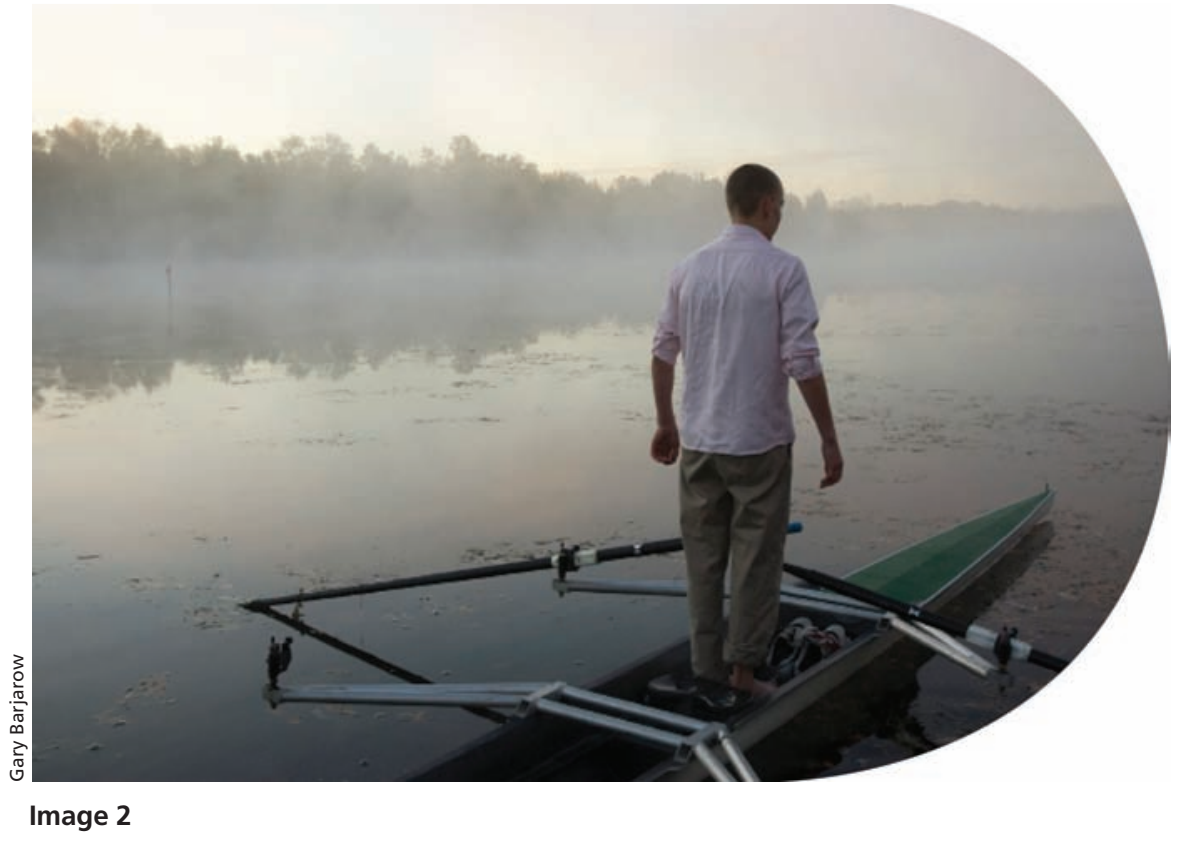

can't

rush it, told to breathe ten times every hour how long do I do this? am I to do it when I walk? they say nothing can happen, but maybe I do something wrong, maybe it rips open

do exactly as they say

no lifting

no reaching

no bending

no driving

\section{but I don't know}

what to do, I don't know how to do it, left with questions, left to figure it out, like I was thrown to the wolves, left to follow instructions to the dotted line, follow exact procedures, but listen to my instincts, faithfully take medications

but don't become addicted do exactly as they say, but listen to my body, don't push myself, but Force, myself to walk
I do the prescribed walks but have to judge my body, have to follow their orders but they're not inside me

they don't know

how - I-feel

left with these things

"don't lift anything heavy"

for how long?

when can I return to work?

should I walk fast?

slow?

does it matter, as long as I walk?

how do I do this?

how can I live?

will I get back

to my old self?

when will I be "normal"?

like I was thrown

to the wolves, I'm left

to figure it out 


\section{These things prey on one's mind}

This poem reveals feelings of turmoil and isolation that participants felt. They described a moment-to-moment/day-to-day physical and emotional struggle in which they lacked support and wished for more communication with practitioners. In Image 3, a figure situated alone in a forest symbolizes feeling lost and caught in an emotional spiral.

the mind is a strange animal

catching

the spirit off guard

can make a heaven of hell,

a hell of heaven. ${ }^{3}$

I had one black

day

one emotional black

black

day

one really dark

down

depressing

day

I couldn't shake it

they said there'd be days

like this, I was warned

they said there' $d$ be mood swings

dark moods

despite a host of warnings

all

of a

sudden,

it came over me

I had no reason,

to feel blue

I was alive

I think it had to do with the medication

the invasion

of my body, having to hold

onto walls when I walked, restricted

by the things I can do, despite

expectations of aches and pains

one sees such aches and pains as possible indicators

of something-seriously-gone-wrong

as days

passed

didn't feel like doing anything

didn't feel like walking

I'm not used to this

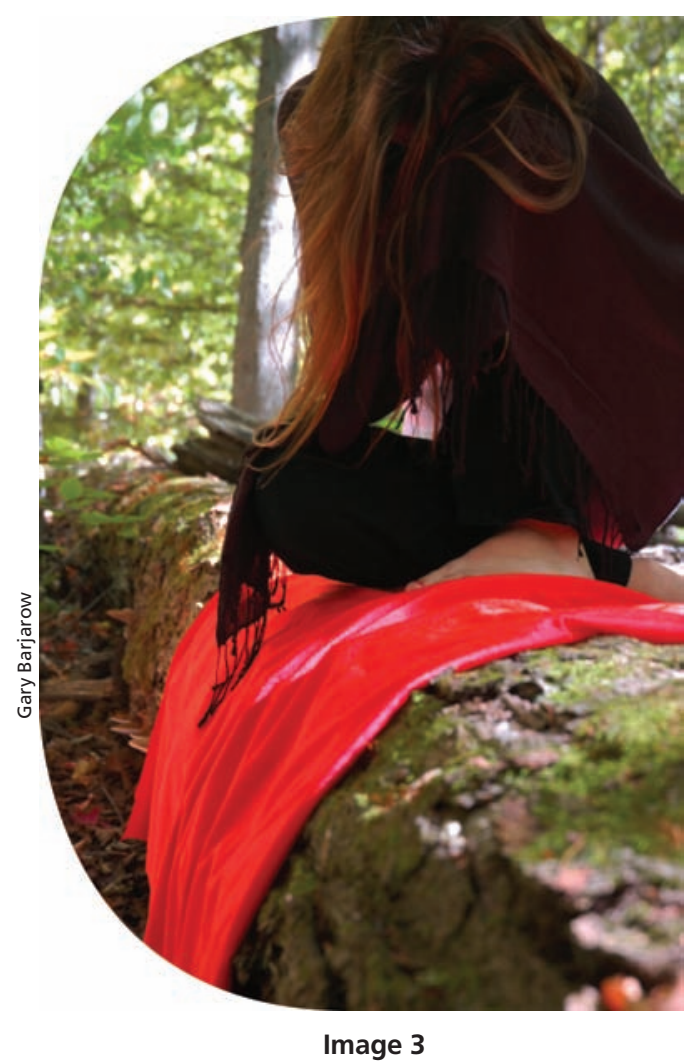

these things Prey

on one's mind

they all say

"you look fine"

I don't feel fine

can't walk

can't do anything

my mind sometimes thinks

I can do things

but my body won't let me

I don't have energy

I feel like crying

I'm useless

helpless

I'm learning

to deal with restrictions, the body

doesn't repair so quickly

goes at its own speed, forces

me to follow, I can't

do all the things I used to, my patience

evaporating

to borrow the words of William Wordsworth

"five years have past;

five summers,

with the length

Of five

long

winters" ${ }^{\prime 4}$ 


\section{Not the demon I thought it would be}

This poem reflects participants' realization that the process is tolerable. As they began to look beyond their current state, participants described a renewed sense of clarity regarding recovery. This is portrayed in Image 4, with a figure standing tall in an open field of snow with hints of foliage emerging. Although the window pane acts as a separation between the figure and outside world, he stands with confidence and readiness to move forward.

three vanishing scars

Forcefully remind me

of my mortality,

wish I could talk

to someone about how I feel

about what's going on inside

I'm not sure if my chest will split open, afraid

to cough and sneeze, scared I might fall

can't sleep through the night I want to beat the records

I just have to Suffer

through it, discovered

I can't rush it, have to work

my way up, I feel sorry

for myself, worried

scared, nothing

is progressing, I feel

Static

frustrated

I'm in no walking mood, I can't

breathe, I can't

drive, I can't

walk, I can't

do anything,

I'm tired

exhausted

lethargic, I can't

help myself, I can't

Stand it, my hands don't

work, I don't

feel like reading, I don't

feel like walking

I Still.

Get. Pain.
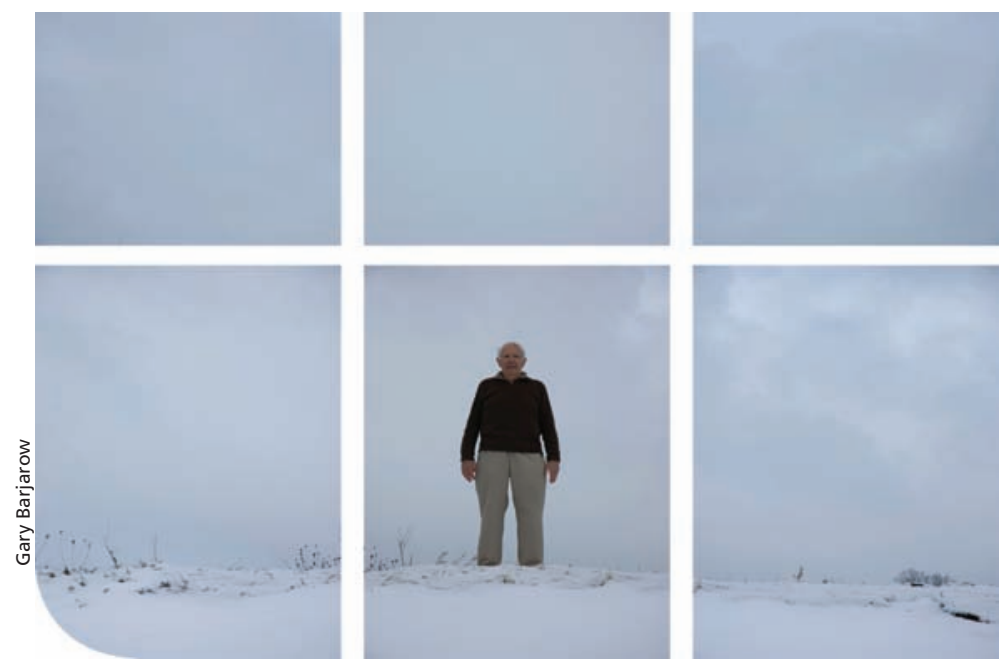

Image 4

but, in the cold light of logic

my current condition is better

I'm breathing

my heart's beating

I'm not what I used to be

get reminders from my Body when I overdo it

that's the way it has to be for now

an incremental return, to normalcy

I have to Hurt to get better

Build myself up

look how far l've travelled

how fast it has gone

I'm getting stronger

it's Worth,

what I did, worth

the pain

the anxiety

the inconvenience

I had my first glass of red wine in five weeks -

it's not the Demon

I thought it would be

the pain was bearable

under the glare of surgery

that of Lesser consequence

assumes its status

I am fortunate

this experience has brought perspective

I'm loved

I'm wanted

I'm sheltered 
Poetry and imagery provide insight into the embodied, emotional and psychological elements of recovery. Once home, contact with practitioners is infrequent and of short duration and the content is not always structured according to patients' needs. This narrative evidence indicates that patients' struggles are impromptu and distressing, leaving them feeling anxious and uncertain. They have difficulty inferring whether their physical sensations are normal parts of recovery.

Our work, and that of others, ${ }^{5}$ confirms that patients lack education, communication and supportive interventions tailored to their needs in the home. The move towards a system that encompasses a patient-centred care philosophy demands that we consider all phases of therapeutics including the home period of recovery.

\section{Jennifer L. Lapum PhD RN}

Associate Professor

Ryerson University

Daphne Cockwell School of Nursing

Kathryn Church PhD MA

Director and Associate Professor

School of Disability Studies

Ryerson University

Terrence Yau MD MSc

Angelo and Lorenza DeGasperis Chair in Cardiovascular Surgery Research and Director of Research in Division of Cardiovascular Surgery
Toronto General Hospital

Professor of Surgery

University of Toronto

Perin Ruttonsha OCGC BA

Design Strategist and Artist

Alison Matthews David PhD BA

Assistant Professor

School of Fashion

Ryerson University

Toronto, Ont.

\section{References}

1. Fredericks S. The influence of country of origin on engagement in self-care behaviors following heart surgery: a descriptive correlational study. J Clin Nurs 2012;21: 2202-8.

2. Lapum J, Ruttonsha P, Church K, et al. Employing the arts in research as an analytical tool and dissemination method: interpreting experience through the aesthetic. Oual Inq 2012;18:100-15.

3. Milton J. Paradise lost. Cambridge (UK): Cambridge University Press; 1952.

4. Wordsworth W. Tintern Abbey. Boston (Mass): Houghton Mifflin Company; 1919

5. Lie I, Bunch E, Smeby N, et al. Patients' experiences with symptoms and needs in the early rehabilitation phase after coronary artery bypass grafting. Eur J Cardiovasc Nurs 2012;11:14-24

Funding: This work was supported by: Canadian Institutes of Health Research, Meetings, Planning and Dissemination Grant (228287); Ryerson University, Faculty of Community Services Seed Grant; and Sigma Theta Tau International Lambda Pi-At-Large Chapter Seed Grant

Acknowledgments: The poetry was composed by Jennifer Lapum.

CMAJ 2013. DOI:10.1503/cmaj.121561 